\title{
MUTAÇÕES NA VARANDA DA CASA BRASILEIRA - EXPLORAÇÕES TIPOLÓGICAS MODERNAS E CONTEMPORÂNEAS
}

CHANGES IN THE BRAZILIAN HOUSE VERANDA - MODERN AND CONTEMPORARY TYPOLOGICAL EXPLORATIONS

\section{GONSALES, CÉLIA}

Doutora, Universidade Federal de Pelotas, celia.gonsales@gmail.com

\section{BALTAR, LAURA}

Graduanda, Universidade Federal de Pelotas, laura.klajn@gmail.com

\begin{abstract}
RESUMO
A varanda é um elemento tradicional na arquitetura brasileira e se configura como antessala de acesso, lugar aprazível de estar ou território de reunião. A varanda, como tantas "estruturas arquitetônicas elementares" semelhantes - stoas, pórticos, loggias -, interage com outras conformando diferentes "estruturas formais". Este trabalho vai tratar especificamente de uma variação da varanda - que chamaremos "varanda conectora" - que aparecerá, a partir de um processo de mutações, tanto na casa moderna como na casa contemporânea brasileira e cuja raiz tipológica pode ser encontrada na casa tradicional. A partir da apreciação da varanda na casa tradicional e na arquitetura moderna, o estudo se desenvolve a partir de quatro exemplos: duas casas do período moderno e duas casas do período contemporâneo que deixam evidente o marco de modernidade de um espaço que se expande em direção à paisagem. Os procedimentos tipológicos de análise e projeto em arquitetura nos auxiliam nesta investigação mostrando-nos a possibilidade de reunião de projetos ou obras de arquitetura com uma estrutura formal ou forma-base em comum. A eficácia desse procedimento fica evidente na indicação que traz consigo de construção de "séries tipológicas": conjunto de projetos que partem de uma mesma forma-base ou de uma mesma "estrutura arquitetônica elementar" que combinadas com outras estruturas sofrem processos de transformação conformando novas estruturas formais. Esse procedimento assume que o projeto sempre é concebido com base em um conhecimento arquitetônico construído a partir de uma série de obras precedentes.
\end{abstract}

PALAVRAS-CHAVE: varanda moderna; varanda contemporânea; estrutura arquitetônica elementar; série tipológica.

\begin{abstract}
The veranda is a traditional element in the Brazilian architecture and is set as the anteroom for access, a pleasant place to be in or a meeting place. The veranda, as other so many similar "elementary architectural structures" - stoas, porticoes, loggias -, interacts with others conforming different "formal structures". The present paper deals specifically with one veranda variation - which we will call "connecting veranda" - which will appear, after a process of changes, both in the modern as well as in the contemporary Brazilian house and whose typological root can be found in the traditional house. Based on the appreciation of the veranda in the traditional house and in modern architecture, the study is carried out based on four examples: two houses from the modern period and two from the contemporary period which highlight the mark of modernity of a space which expands towards the landscape. The typological procedures of analysis and project in architecture help us in this investigation showing us the possibility of gathering projects or architecture works with a formal structure or base-form in common. The efficiency of this procedure is evident in the indication which brings with it a construction "typological series": a group of projects which arise from a similar baseform or from the same "elementary architectural structure" which, arranged with other structures suffer processes of transformation conforming new formal structures. This procedure assumes that the project is always conceived based on architectural knowledge built from a series of precedented works.
\end{abstract}

KEY-WORDS: modern veranda; contemporary veranda; elementary architectural structure; typological series.

\section{INTRODUÇÃO: A VARANDA CONECTORA}

Definida, em geral, como um espaço com cobertura e sem fechamento vertical, a varanda é um elemento tradicional na arquitetura brasileira. Trazida ao Brasil, por portugueses (Lemos, 1996; Brandão e Martins, 2007), se adaptou ao clima e modo de viver deste país. Considerada um espaço "intermediário" que pode ser externo, conformando-se como prolongamento do telhado, ou interno, sendo embutido no corpo da casa. Antessala de acesso, lugar aprazível de estar ou território de reunião, a varanda estabelece um limite entre o espaço público e o privado, entre o sagrado e o profano (figura 1). 
Figura 1 - Varanda em arquitetura civil e religiosa. a) Casa do Bandeirante. b) Igreja de São Miguel Paulista

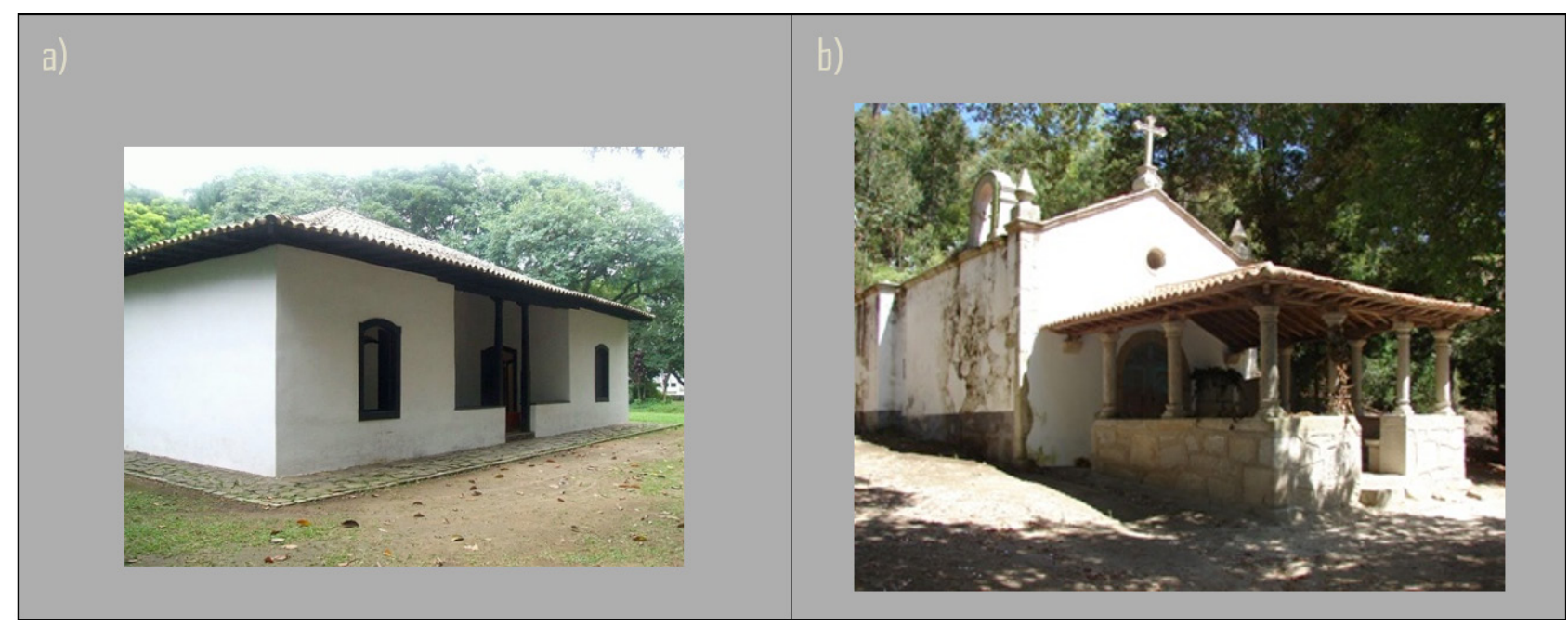

Fonte: Wikimedia Commons: a) autor: Carlos Alkmin; b) autor: Jorgeguedessilva

A história da arquitetura está repleta de "estruturas arquitetônicas elementares" (Marti Aris, 1993) conformadas como abrigos externos aos edifícios - stoa, pórtico, loggias. Formas que possuem uma clara identidade e que podem interagir com outras, formando estruturas mais complexas, como praças, claustros, templos, palácios, casas e igrejas. A casa tradicional brasileira apresenta variáveis de combinações dessas estruturas elementares. Helena Brandão e Angela Martins (2007) indicam algumas (figura 2).

Figura 2 - Indicação da varanda na casa tradicional brasileira (em verde): a) Alpendre. Fazenda de engenho do Capão do Bispo. Rio de Janeiro, RJ. b) Entalada. Casa do Butantã. São Paulo, SP. c) Copa/Sala de Jantar. Sobrado Colonial.

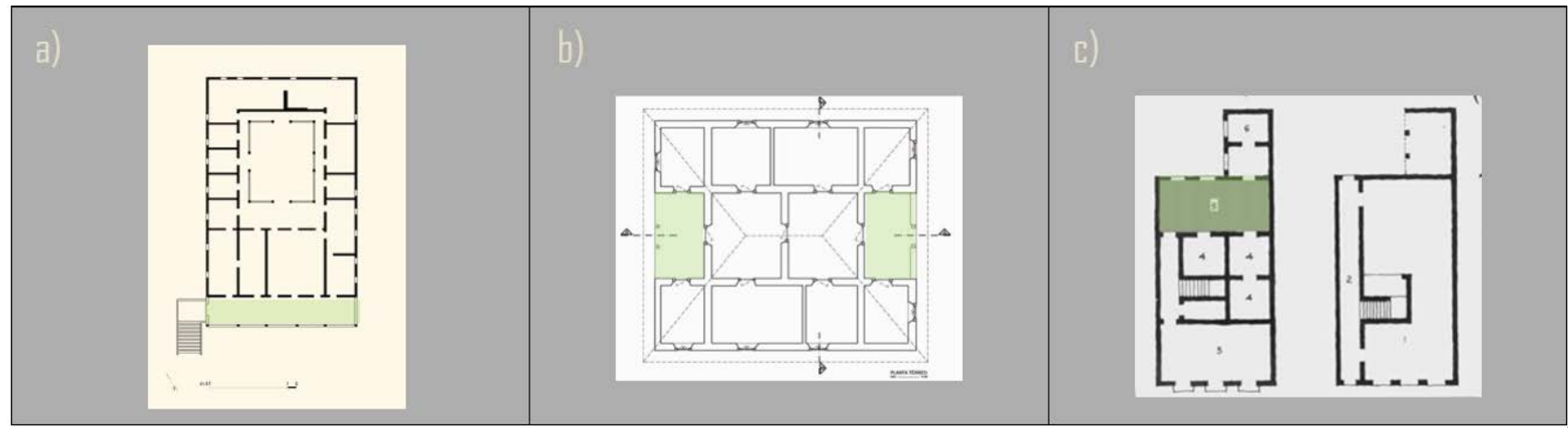

Fonte: Edição do autor sobre imagem publicada em: a) http://www.casaruibarbosa.gov.br/acasasenhorial/index.php/casas-senhoriais/ pesquisa-avancada/39-fichas/446-engenho-do-capao-do-bispo; b) http://blog.hsvab.eng.br/2010/09/22/casa-bandeirista-do-butanta/; c) REIS FILHO, N. G. Quadro da arquitetura no Brasil. São Paulo: Perspectiva, 1978.

O primeiro exemplo (a) mostra a varanda como uma extensão da casa na parte da frente - em geral também uma extensão do telhado - que, segundo alguns autores (p. ex. Lemos, 1996), é a variação tipicamente brasileira. O exemplo (b) mostra uma varanda muito utilizada na casa bandeirista e que consiste basicamente em uma sala onde uma das paredes é retirada.

A terceira variação de varanda (c) se constitui como um tipo particular de varanda no Brasil e é a que mais se relaciona com a análise realizada neste trabalho. É um espaço fechado conhecido como "copa" ou sala de jantar, situado na parte posterior da casa, o qual atua como elemento de ligação entre o corpo principal e a cozinha, localizada nos fundos junto ao quintal. De acordo com Lemos (1996), a casa portuguesa, quando implantada no Brasil, se apropriou de costumes indígenas e expulsou para o lado de fora o preparo das refeições. Essa atitude criou uma casa binuclear - corpo principal e cozinha - que passa a ser conectada por um espaço coberto. Esse lugar agradável, como comenta o autor, onde a família se reúne, mais tarde dará origem à sala de jantar ou copa. Nesse caso, a varanda começa a adquirir outro status no arranjo da casa: espaço organizador, distribuidor, conector; vai se tornando mais centralizado e de importância crescente na composição da residência. 
Este trabalho irá tratar especificamente dessa variação da varanda - a qual chamaremos de "varanda conectora" - que aparecerá, a partir de algumas mutações, tanto na casa moderna como na casa contemporânea brasileira. Para o estudo utilizaremos quatro exemplos como objeto de análise: Casa Hermenegildo Sotto Maior (1942) em Araruama, RJ, do arquiteto Aldary Henriques Toledo; Casa Maria Carlota de Macedo Soares (1951), em Petrópolis, RJ, do arquiteto Sérgio Bernardes; Casa em Praia Preta (2007), SP, e Casa em São Francisco Xavier (2009), SP, estas duas últimas projetadas pelo Escritório Nitsche Arquitetos Associados (figura 3).

Os exemplos de 1942 e 1951 foram escolhidos porque, no universo de projetos observados com varanda "conectora" dentro período do abarcado pela arquitetura moderna - aproximadamente da década de trinta à de sessenta -, apresentam de maneira muito clara as características da variação de varanda foco objeto deste estudo. Por outro lado, a produção projetual do Escritório Nitsche Associados faz parte da amostra geral de arquitetura residencial que compõe as investigações da pesquisa "A casa contemporânea brasileira" (1), da qual as autoras são colaboradoras. O fato de o escritório fazer amplo uso de varandas, e em geral varandas conectoras, em sua arquitetura residencial não urbana nos levou à escolha de suas obras para esta análise.

Figura 3 - a) Casa em Praia Preta. b) Casa em São Francisco Xavier.

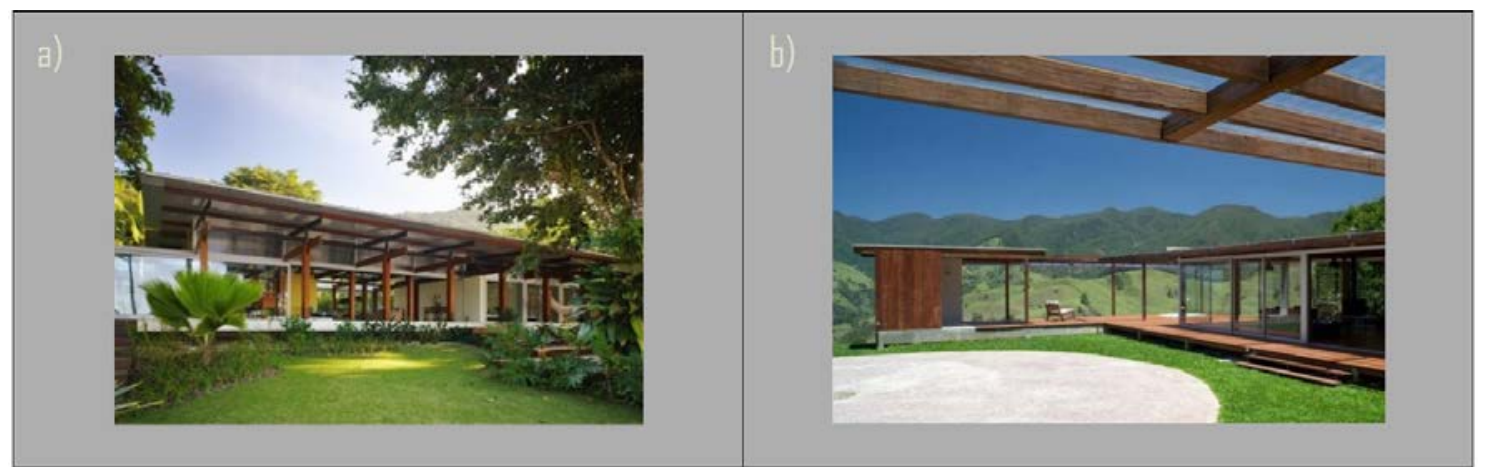

Fonte: http://www.nitsche.com.br

Os procedimentos tipológicos de análise e projeto em arquitetura - com os quais viemos trabalhando na pesquisa anteriormente citada - nos auxiliará neste estudo. O essencial desse instrumento é a possibilidade de reunião de projetos ou obras de arquitetura com uma forma-base comum, como indicou Giulio Carlo Argan (1965), ou com uma estrutura formal em comum, como definiu Carlos Martí Arís (1993).

A eficácia desse procedimento em termos de análise fica evidente na indicação que traz consigo de construção de "séries tipológicas", conjunto de obras ou projetos que partem de uma mesma estrutura formal, mas onde se observa transformações a partir de exemplos anteriores. Por outro lado, sua validade em termos de procedimentos projetuais se baseia no fato de que o método tipológico incorpora a ideia de repetição, porém uma repetição que admite e estimula a transformação.

\section{A VARANDA: VARIAÇÕES E MUTAÇÕES MODERNAS}

A varanda - ou um similar espaço coberto/aberto - aparece na arquitetura moderna europeia, conhecida referência para a arquitetura brasileira. O pilotis como espaço intermediador entre interior e exterior, poderia ser considerado o correspondente da varanda tradicional na arquitetura moderna. Mas na casa corbusiana, por exemplo, esse espaço não desempenha o papel social e aglutinador do seu correspondente na arquitetura histórica.

No entanto, no segundo e terceiro esquemas de suas "quatro composições", Le Corbusier, indica a presença de um espaço correspondente a uma varanda. Na segunda, correspondente à Villa Stein, além do terraço, também há um espaço de pé direito duplo, com ausência de paramento vertical, mas com presença de plano de cobertura e que dá acesso ao jardim posterior (figura 4). Na terceira composição - Villa Baizeau - além do pilotis, o arquiteto expõe uma espaço coberto/aberto no último pavimento da casa como alternativa ao terraço-jardim.

Em contrapartida, a loggia - espaço tradicional com cobertura, mas aberto como uma estância exterior - está presente em parte da arquitetura moderna residencial italiana - ver, por exemplo, a varanda/loggia no terraço da Casa do Viticultor, na Suíça, de Alberto Sartoris. 


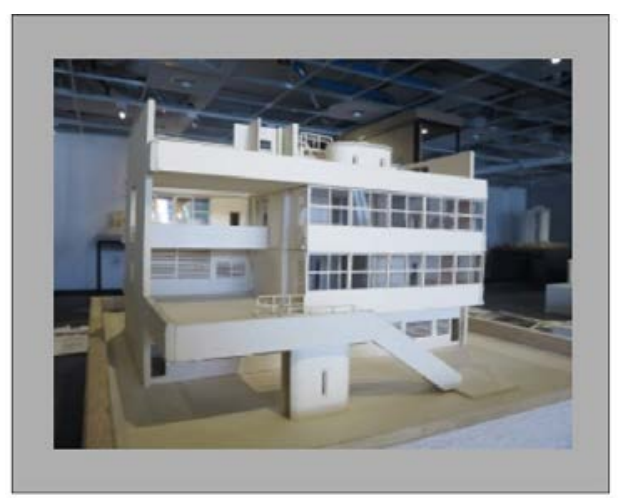

Fonte: Forgemind ArchiMedia

No Brasil, a conformação da varanda na casa moderna tem suas peculiaridades. Em primeiro lugar poderíamos mencionar o fato de que, tal é a força cultural desse elemento na morada brasileira, que o pilotis é indicado como um lugar de estar e descanso, por exemplo, nos desenhos de Lúcio Costa para as suas "casas sem dono" do começo dos anos trinta. A presença de redes e cadeiras deixa clara a apropriação desse espaço em clima tropical. Por outro lado, o uso da varanda na arquitetura moderna brasileira está diretamente relacionado ao recorrente uso do telhado nas residências - que de alguma maneira cria uma conexão com a varanda tradicional deste país (2).

No entanto, os novos princípios de projeto do século XX, próprios das estratégias modernas de construção formal, decompõem a obra em volumes independentes e, desse modo, a varanda começa a aparecer dentro de uma variedade de arranjos organizacionais e compositivos. Essa "estrutura elementar", porém, mantém-se sempre como um espaço importante e repleto de significados para as moradias. As varandas externas, as salas-varandas, as varandas vestíbulos, as galerias e as "varandas conectoras" são alguns exemplos do caráter que esse elemento passa a assumir nas variadas estruturas formais da morada brasileira moderna (figura 5).

Figura 5 - Indicação das variações de varandas modernas (em verde): a) Varanda em várias faces. Casa de Campo. Petrópolis, RJ. 1955. Arq. Firmino Saldanha. b) Varanda-galeria. Casa do arquiteto. Rio de Janeiro, RJ. 1960. Arq. Sérgio Bernardes. c) Varanda-acesso. Casa caseiros de Paulo Bittencourt. Petrópolis, RJ. 1951. Arq. Sérgio Bernardes. d) Varanda-pilotis. Casas sem dono. Rio de Janeiro, RJ. 1931 -35. Arq. Lucio Costa. e) Varanda/sala. Casa na Gávea. Rio de Janeiro, RJ. 1948. Arq. Paulo Antunes Ribeiro. f) Galeria conectora. Casa Pedro Paulo Paes de Carvalho. Araruama, RJ. 1944. Arq. Lucio Costa. g) Sala/varanda conectora. Casa do arquiteto. Nova Friburgo, RJ. 1949. Arq.

Carlos Ferreira. h) Sala/varanda conectora. Casa Hermenegildo Sotto Maior. Araruama, RJ. 1942. Arq. Aldary Henriques Toledo.

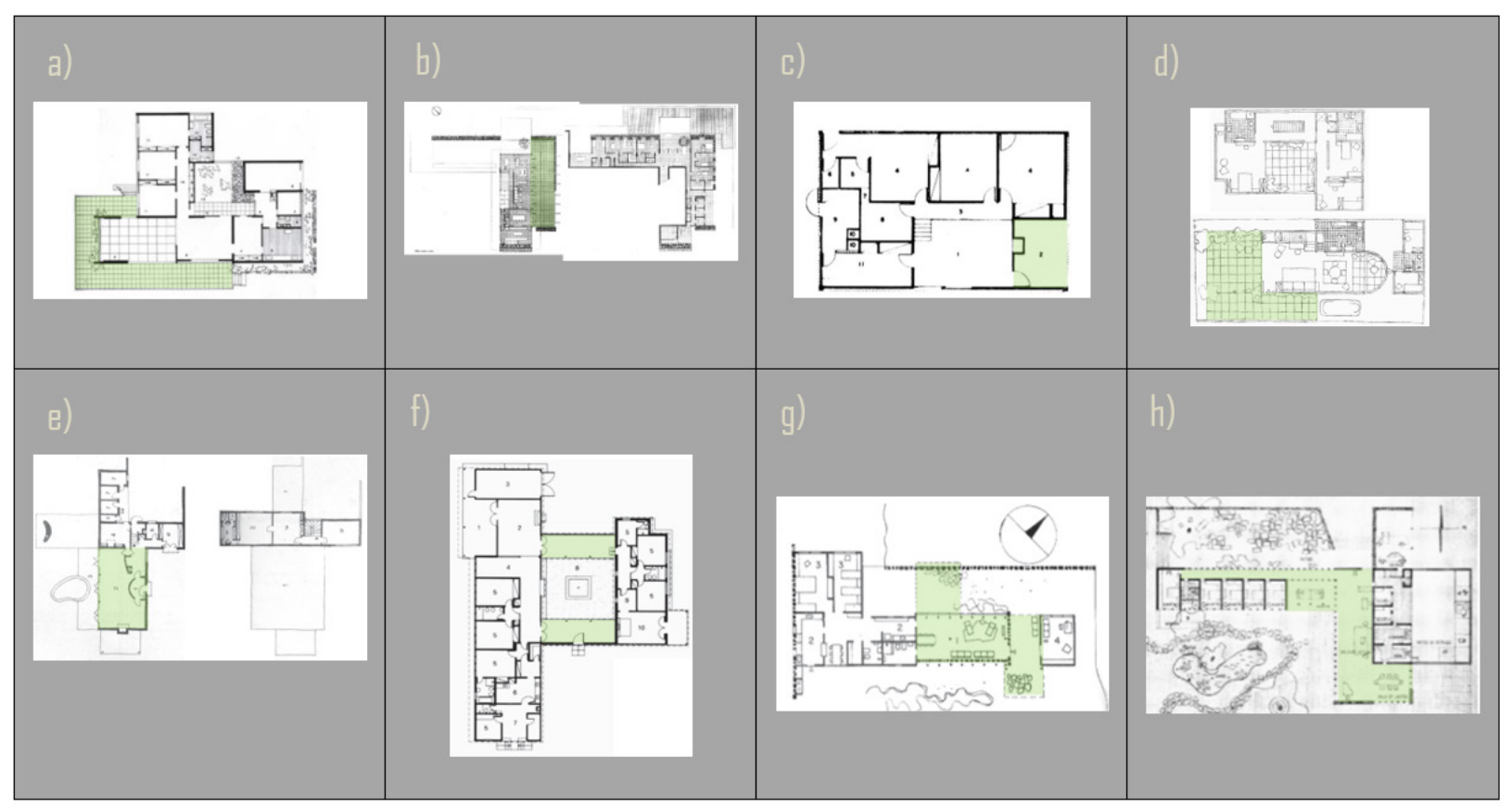

Fonte: Ediçăo do autor sobre imagem publicada em: a) e e) ACB 2, Rio de Janeiro, 1948; b) Acrópole 301, Săo Paulo, 1963, p.7;

c) L'Architecture d'Aujourd'hui , Paris, n. 42-43-Brésil, ago. 1952; d) COSTA, L. Registro de uma vivência. São Paulo: Empresa das Artes,1995, p 85; f) WISNIK, G. Lucio Costa. São Paulo: Cosac \& Naify, 2001, p. 79; g) MINDLIN, 2000, p. 54; h) GOODWIN, 1943, p. 177. 
O exemplo de "varanda conectora" na arquitetura moderna (figura $5 \mathrm{~g}$ e $5 \mathrm{~h}$ ) é aquele que a transforma em elemento "mais central", não somente em um sentido geométrico, mas também hierárquico. Nesse caso, esse elemento adquire um protagonismo mais determinante como o lugar da vida cotidiana, das relações entre os moradores, dos encontros de "caminhos" percorridos. Se na casa tradicional essa varanda aparecia unindo dois núcleos da casa cozinha e corpo principal - e configurando um espaço de refeições aprazível, em alguns exemplos da arquitetura moderna, vira o espaço central: a sala-varanda (figura 6).

Em termos espaciais, ela se configura como um espaço expansivo a partir de uma composição centrífuga, cujas principais propriedades são a fluidez, o dinamismo e a abertura. Mas essa varanda "mirante" - mira em direção ao horizonte -, apesar da exposição ao exterior, está também dentro: está no centro, está "entre" a vida da casa.

Figura 6 - Indicação varandas conectoras unindo volumes (em verde): a) Casa do Arquiteto. Nova Friburgo, RJ. 1949. Arq. Carlos Ferreira. b) Casa Olivio Gomes. São José dos Campos, SP. 1954. Arq. Rino Levi. c) Casa Hermenegildo Sotto Maior. Araruama, RJ. 1942. Arq. Aldary Henriques Toledo. d) Casa Maria Carlota de Macedo Soares. Petrópolis, RJ. 1951. Arq. Sérgio Bernardes.

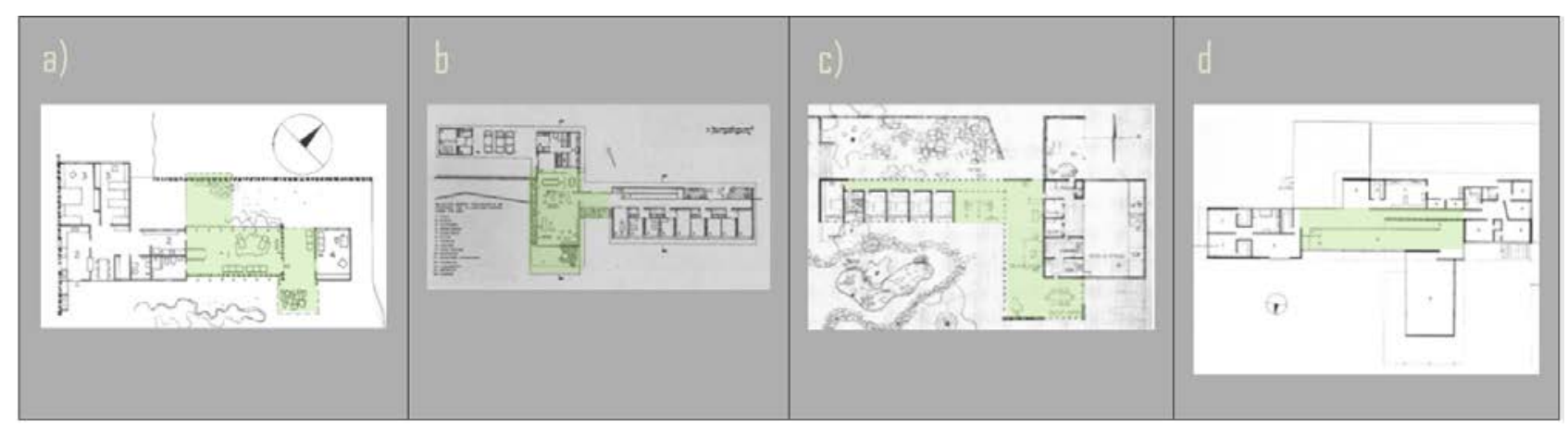

Fonte: Edição do autor sobre imagem publicada em: a), b) e d) MINDLIN, 2000, p. 54, 92 e 78, respectivamente; c) GOODWIN, 1943, p. 177.

Observemos com mais detalhe duas casas modernas: Casa Hermenegildo Sotto Maior (Fazenda São Luis) de Aldary Henriques Toledo, de 1942 e a Casa Maria Carlota de Macedo Soares de Sérgio Bernardes, de 1951. A primeira fica junto ao lago de Araruama e localiza-se em terreno com relevo acidentado, da mesma forma que a segunda, na Serra dos Órgãos, e ambas possuem uma vista generosa para a bela paisagem.

A recorrente composição - na arquitetura moderna - com vários volumes caracteriza ambas as casas. O partido em cruz (Casa Hermenegildo) ou em T (Casa Maria Carlota) permite um arranjo ágil entre todas as alas e uma facilidade na adaptação ao relevo. A Casa Hermenegildo apresenta uma composição dividida em volumes de dimensões equilibradas, conectados pelo corpo da sala. Já a Casa Maria Carlota de Macedo Soares mostra predomínio de um volume horizontal longitudinal, com um corpo secundário e transversal. A particularidade nessas composições é que no encontro dos eixos, ou seja, no "coração" da casa, se localiza a varanda e/ou a sala/ varanda. Desse modo esse espaço se apresenta como elemento de conexão entre os vários setores (figura 7).

Figura 7 - Organização volumétrica e posição da varanda (em verde). a, b, c, d) Casa Hermenegildo Sotto Maior. e, f, g, h) Casa Maria Carlota de Macedo Soares.

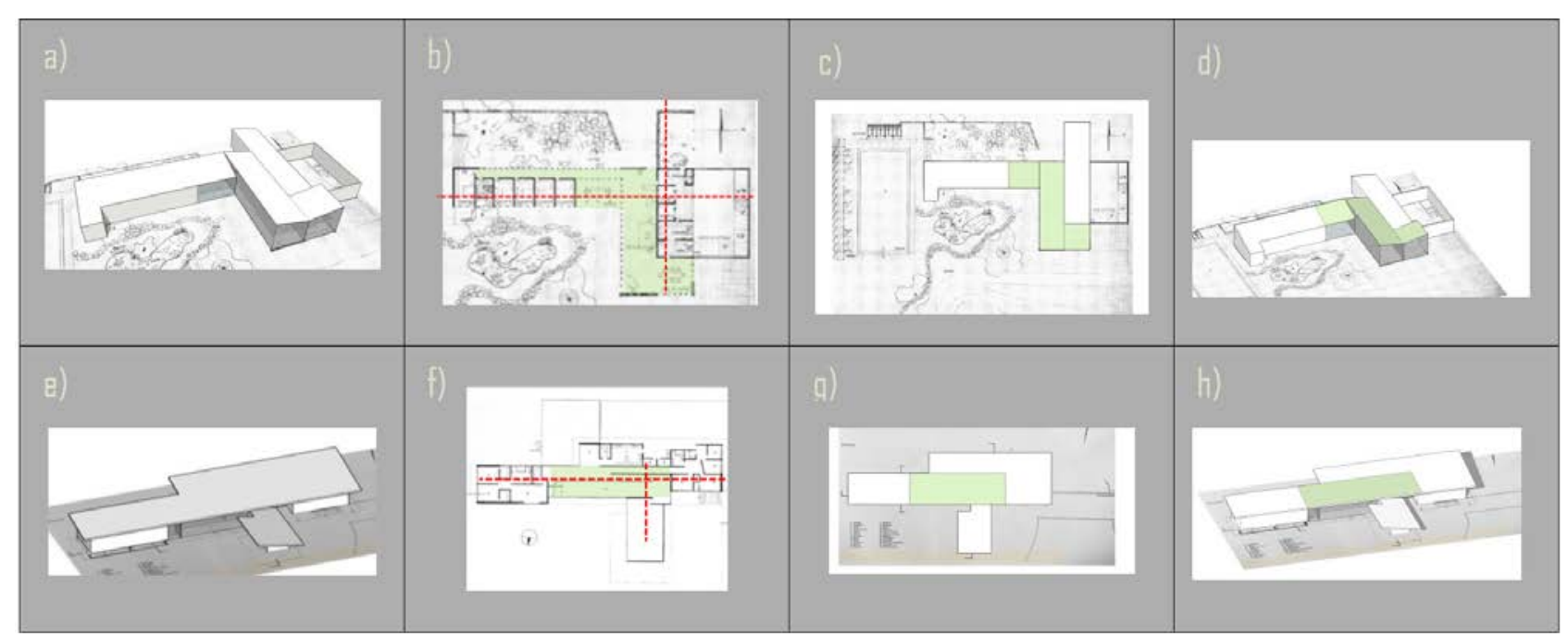

Fonte: Autor 
Na Casa Hermenegildo Sotto Maior a varanda e a sala/varanda em L atua como elemento de transição, separando e unindo os dois nítidos volumes que abrigam os setores íntimo e de serviço. Já a Casa Maria Carlota de Macedo Soares a varanda/galeria-de-arte alongada faz a conexão, sob uma mesma cobertura, de três volumes - um contém o setor íntimo, o outro o setor de hóspedes e o terceiro o setor de serviços. (figura 8). A sala de estar como um volume à parte, cercada por um alpendre, é o quarto corpo conectado ao restante da casa pela varanda.

Figura 8 - Zoneamento: vermelho - setor íntimo; amarelo - setor social; azul - setor de serviço. a) Casa Hermenegildo Sotto Maior b) Casa Maria Carlota de Macedo Soares.

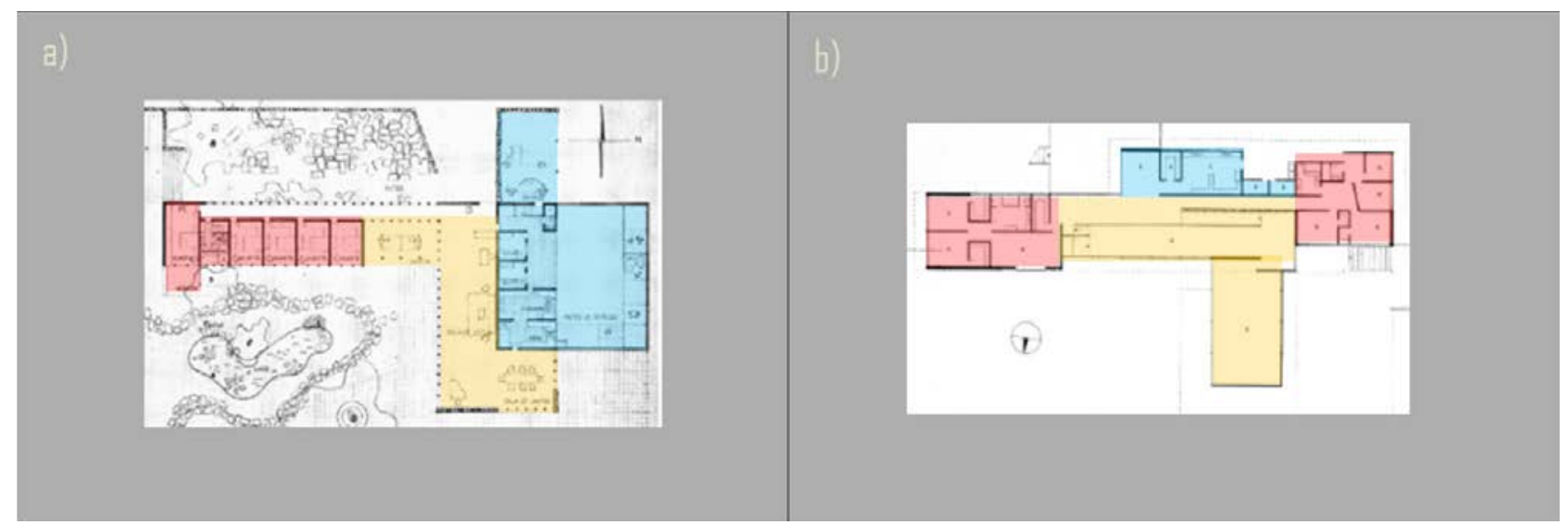

Fonte: Edição do autor

Desse modo, a peculiaridade dessa variação da varanda reside não somente no fato de estar no "centro" - ou "entre", mas também por se constituir como um elemento poroso, transparente, entre dois ou mais sólidos. Essa transparência é favorecida por uma estrutura muito leve. Na casa Hermenegildo, a trama estrutural de madeira se estende por toda a casa adquirindo um destaque na varanda e na sala/varanda a partir do amplo espaço que caracteriza esses lugares e do contraste com a expressão estereotômica das paredes de pedra. Já na Casa Maria Carlota, a trama de estrutura metálica aparece na varanda/galeria/estar, na sala de estar, nos alpendre e circulações externas e contrasta com as paredes portantes das alas, bem como com as paredes de pedra.

\section{A VARANDA CONECTORA: CONTINUIDADE CONTEMPORÂNEA}

A varanda como estrutura arquitetônica elementar se relaciona com outros elementos configurando arranjos mais complexos. A "varanda conectora" se apresenta em estruturas formais da casa contemporânea de maneira semelhante às das casas modernas.

Embora essa variação de varanda apareça em partidos lineares dos projetos do Escritório Nitsche Arquitetos (figuras 9a e 9b), são os partidos compostos, que configuram espaços mais complexos e elaborados (figuras 9c e 9d), os que interessam a esta análise. Nestes últimos se dá um tipo de arranjo que, como foi visto na arquitetura moderna, caracteriza a varanda como organizadora dos vários corpos ou volumes, como elemento essencial da distribuição espacial e funcional, enfim, como "centro".

Figura 9 - Indicação da varanda conectora nas casas do Nitsche Arquitetos Associados (em verde): a) Casa na Barra do Sahy. Barra do Sahy, SP. 2002. b) Residência em Piracaia. Piracaia, SP. 2012. c). Residência em Praia Preta. Praia Preta, SP. 2007. d) Residência em São Francisco Xavier. São Francisco Xavier, SP. 2009.

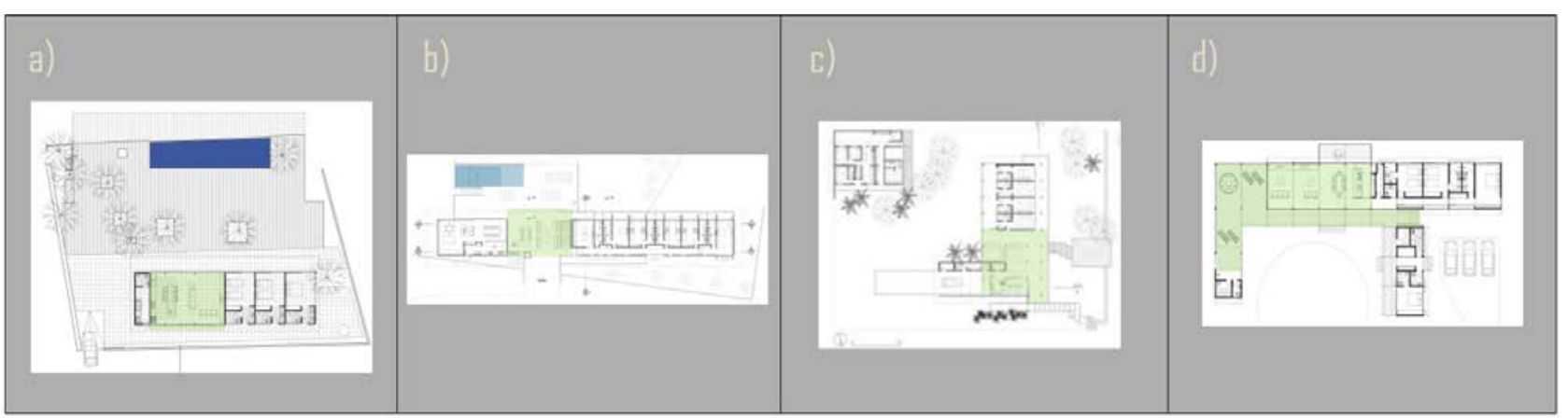

Fonte: Autor 
A varanda conectora é uma estrutura arquitetônica elementar que aparece essencialmente fora de centros urbanos. Ela acontece em estruturas formais que demandam espaço e abertura. A Casa em Praia Preta (2007) encontrase implantada em vasto lote praiano com pouca pressão de seus limites sobre os procedimentos projetuais. A Casa em São Francisco Xavier (2009) localiza-se em grande terreno de caráter rural onde houve a possibilidade de conformação de espaços que se estendem em direção à paisagem, ao horizonte.

Ambas apresentam "formas-base" compostas por alas lineares, organizadas através de volumes independentes - dois volumes na Praia Preta ${ }^{(3)}$ e três volumes na São Francisco Xavier. Na primeira uma composição em L, na segunda, o mesmo partido está acrescido de um volume ortogonal ao corpo mais alongado e principal da casa. Na esquina do $L$, em ambas as casas, conectando os dois corpos lineares, está implantada varanda/sala seguida de alpendre (figura 10).

Figura 10 - Organização volumétrica e posição da varanda (em verde). a) Casa em Praia Preta. Praia Preta, SP. 2007. b) Residência em São Francisco Xavier. São Francisco Xavier, SP. 2009. Nitsche Arquitetos.

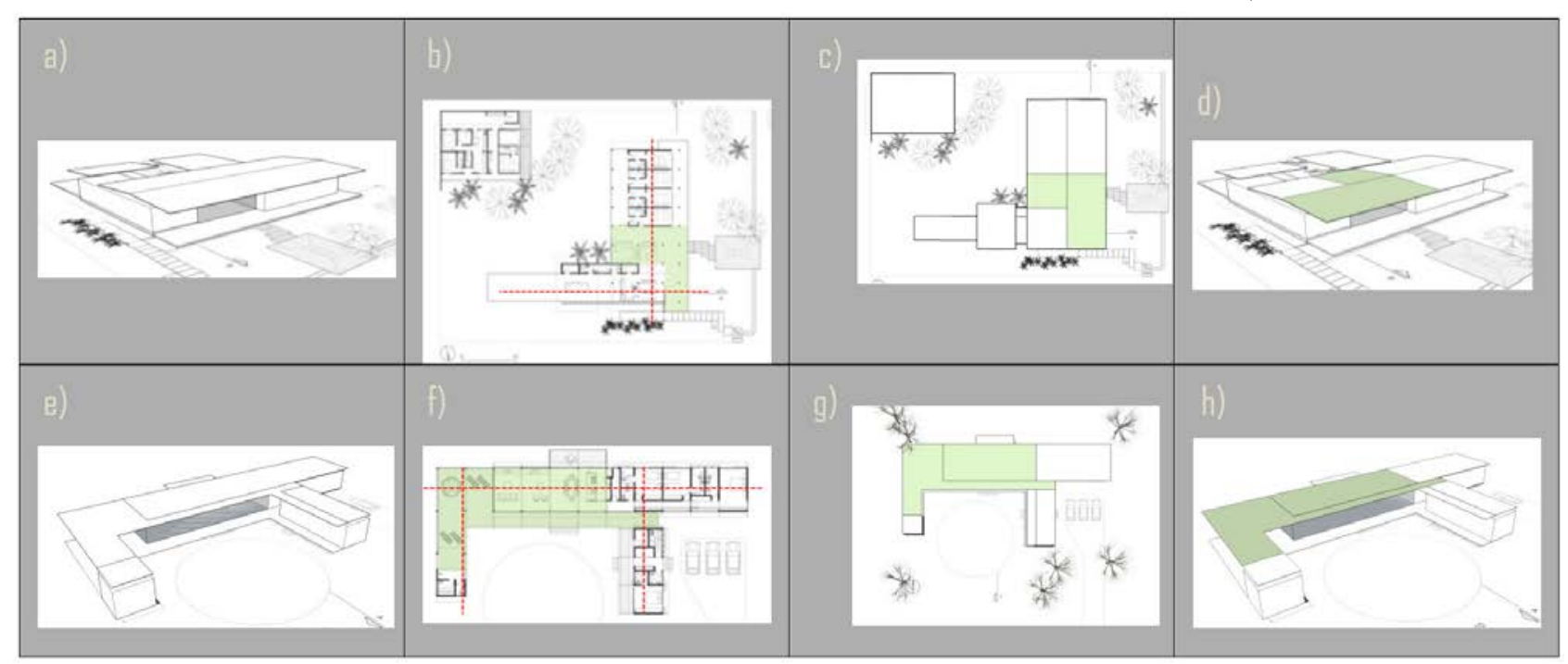

Fonte: Autor

A residência em Praia Preta é composta por dois setores independentes. Um abriga a área íntima e o outro contempla o serviço. Estes setores estão interligados pela varanda, onde se encontra o setor social da residência. Na residência em São Francisco Xavier o extremo do corpo principal recebe a área íntima. O serviço se localiza nos volumes transversais: no extremo sul da fita periférica e no extremo norte do segundo corpo. Este último também contém os quartos de hóspedes. A varanda se encontra no volume principal, abrigando a área social e agindo como elemento de transição entre as partes da casa (figura 11).

Figura 11 - Zoneamento: vermelho - setor íntimo; amarelo - setor social; azul - setor de serviço. a) Casa em Praia Preta. b) Casa São Francisco Xavier

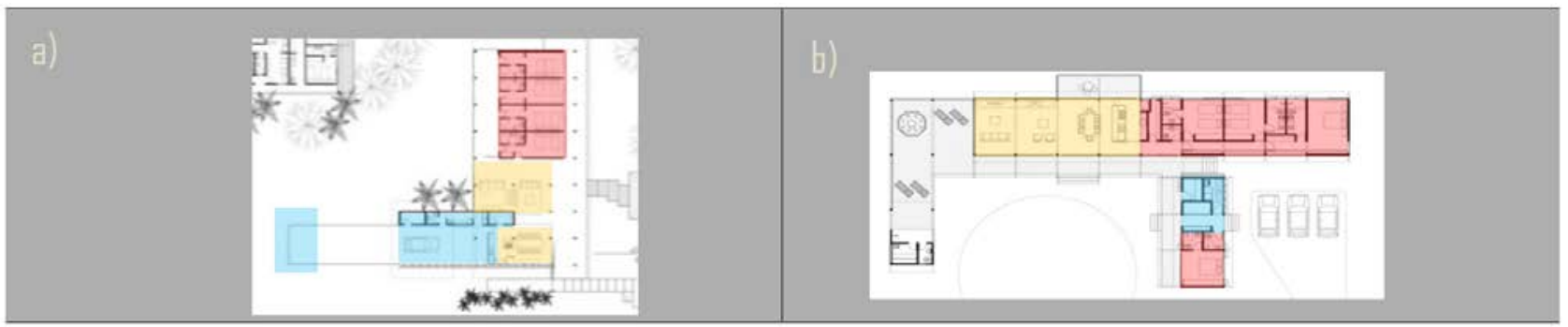

Fonte: Autor

Na Praia Preta, uma grande cobertura com estrutura de madeira e telhas com pouco caimento reúne os dois volumes/setores a partir de uma varanda central que se estende a modo de alpendre e envolve a ambos. A porosidade no núcleo da casa interliga frente e fundos, mar e quintal.

Em São Francisco Xavier, em princípio se pode dizer que três coberturas de duas águas com pouquíssima inclinação estão unidas por um alpendre com cobertura transparente. No entanto a experiência espacial detecta - assim como na Praia Preta - os corpos/setores unidos por uma grande cobertura que acolhe no centro a varanda, ora descoberta, ora coberta verticalmente com vidro, sempre em uma transparência absoluta conectando visualmente norte e sul, lado leste e lado oeste. 
Figura 12 - Grande coberturas e porosidade - vazio entre dois cheios. a, b) Casa em Praia Preta. c, d) Casa em São Francisco Xavier.

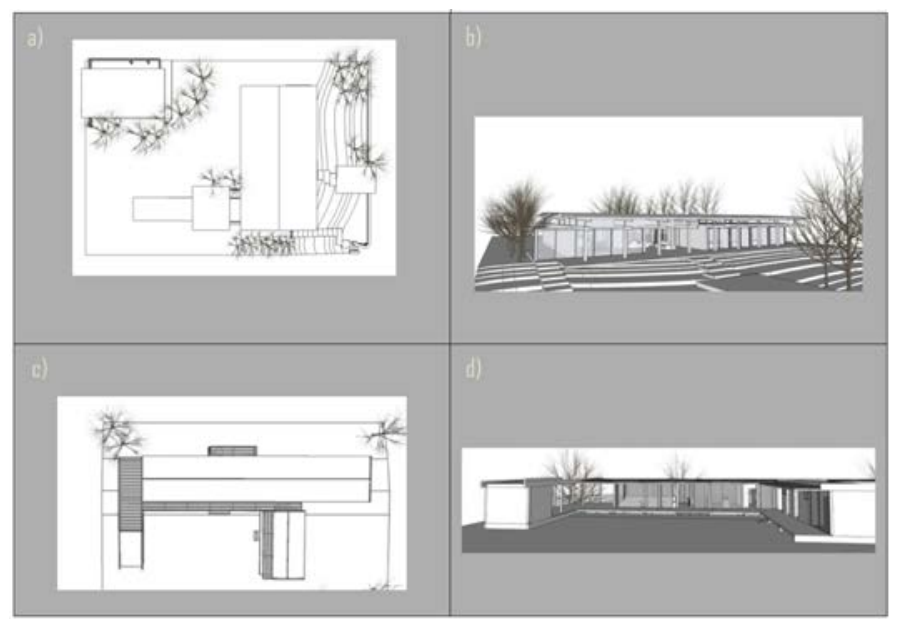

Fonte: Autor

O caráter leve e transparente das varandas é acentuado pela estrutura modular de madeira. Como a maioria das casas projetadas pelos arquitetos Nitsche para espaços abertos, nestas também a estrutura em esqueleto obedece a uma rigorosa modulação e organiza toda a construção.

A residência em São Francisco Xavier evidencia uma modulação regular que deixa à mostra o grande esqueleto estrutural de madeira. A malha desta modulação é rotacionada para organizar os volumes transversais. Já na Residência em Praia Preta é utilizada uma modulação estrutural regular na direção transversal ao volume principal e uma variação modular na outra direção, em uma clara acomodação ao programa (figura 13 a e b).

As casas do Escritório Nitsche Arquitetos costumam ser concebidas como grandes abrigos, grandes varandas (figura $13 \mathrm{c} \mathrm{e} \mathrm{d),} \mathrm{que} \mathrm{acolhem} \mathrm{o} \mathrm{programa} \mathrm{em} \mathrm{volumes} \mathrm{opacos} \mathrm{nas} \mathrm{extremidades,} \mathrm{deixando} \mathrm{as} \mathrm{transparências}$ no centro conjunto, conformando, assim, amplas varandas (figura 13 e e f).

Figura 13 - Cobertura como grande abrigo: estrutura, modulação e cobertura. a, c, e) Casa em Praia Preta. b, d, f) Casa em São Francisco Xavier.

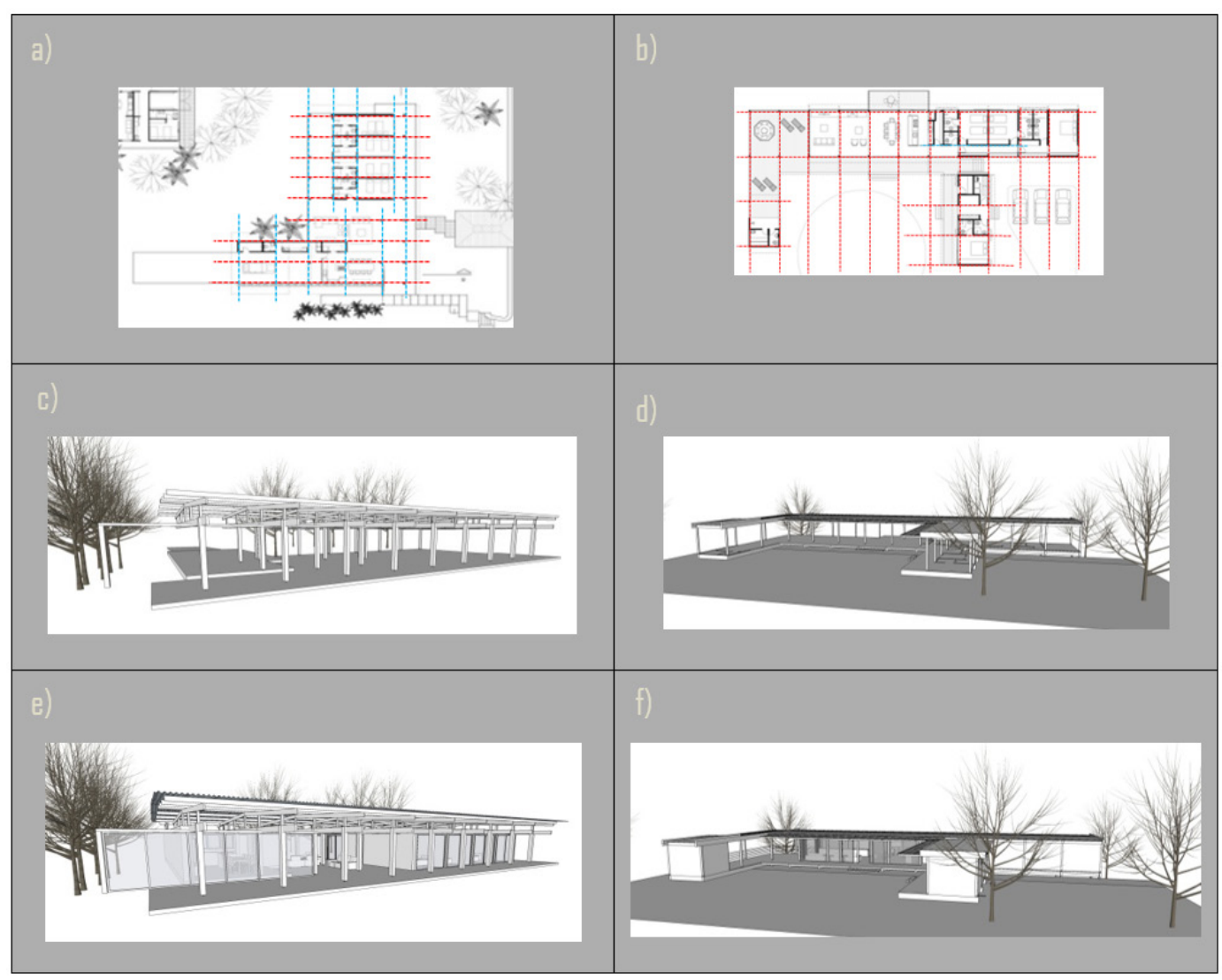

Fonte: Autor 
As varandas dentro de tal estrutura formal estabelecem, tanto na arquitetura contemporânea como na moderna, nos casos que estamos abordando, uma casa polinuclear e conformam uma ideia de porosidade - uma varanda transparente, entre dois sólidos - disposição muito usual na arquitetura moderna brasileira. Carlos Eduardo Comas (1986) já havia chamado a atenção para essa porosidade conformada pelo vazio entre dois sólidos como uma característica peculiar da arquitetura do Brasil, o que pode ser observado no Ministério de Educação e Saúde, na Casa do Baile e em tantas outras obras importantes das décadas de trinta e quarenta do século XX. A acomodação do programa em duas ou mais partes cria essa abertura, através da qual o espaço externo não somente penetra na casa como a perpassa. E é exatamente nesse "vazio", nessa abertura, nessa "fissura", enfim, que se localiza a varanda.

Figura 14 - "Porosidade" nas casas modernas e contemporâneas. a) Casa Hermenegildo Sotto Maior b) Maria Carlota de Macedo Soares c) Casa em Praia Preta d) Casa em São Francisco Xavier

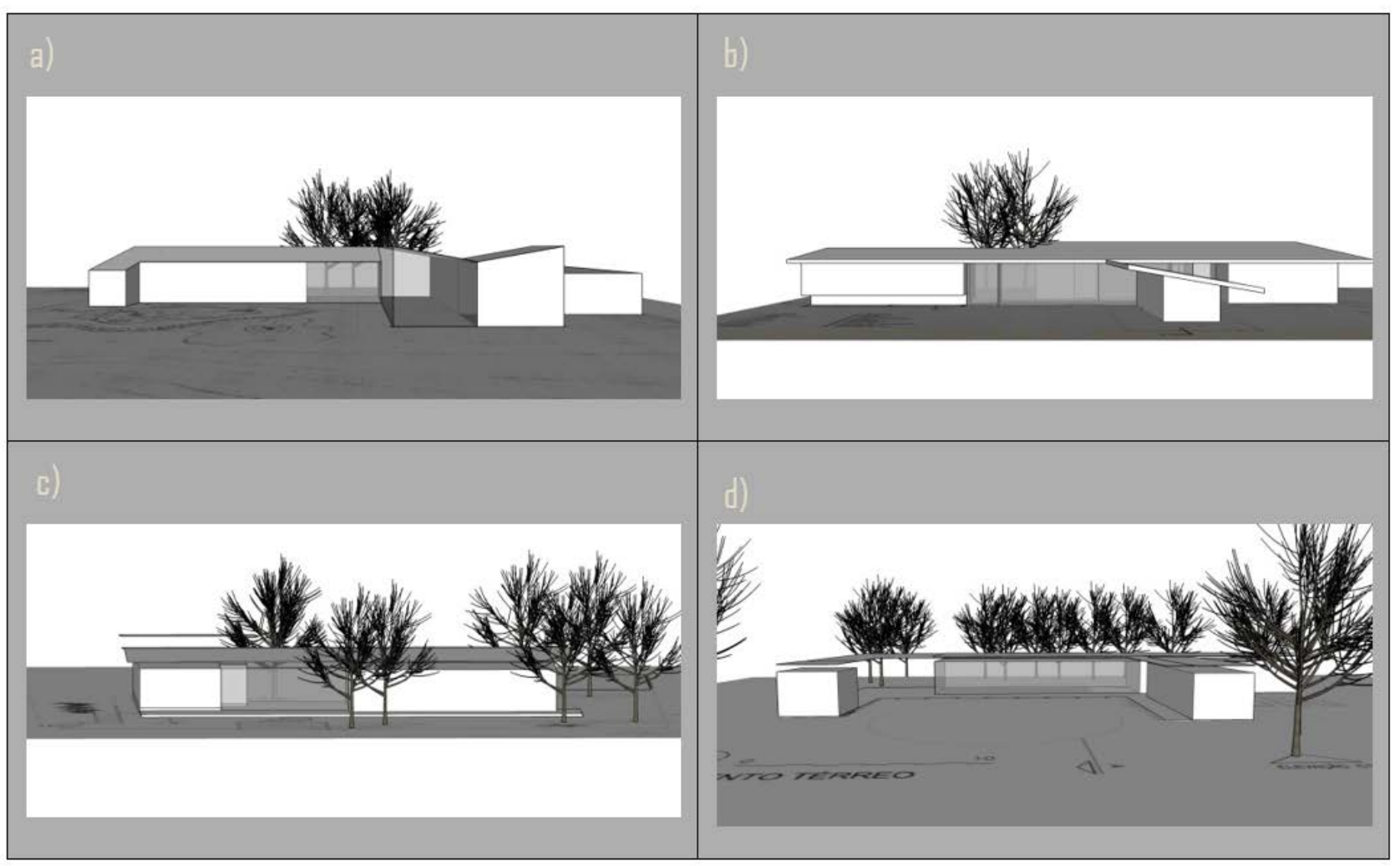

Fonte: Autor

\section{CONSIDERAÇÕES FINAIS}

A varanda moderna e contemporânea tem pontos de interface com a varanda tradicional: a conciliação entre interior e exterior, seu importante caráter social, lugar de descanso e de encontros da vida cotidiana. Esse elemento de fruição da vida doméstica vai se transformando, como vimos, em alguns casos da arquitetura moderna em um centro nevrálgico da casa. Nesse caso, embora não esteja no centro, ela está "entre" as partes, lugar onde caminhos e recorridos se entrecruzam.

Não está no centro como o pátio tradicional - na casa-pátio. Mas a varanda conectora, por seu status destacado na estrutura social e espacial da casa, por seu caráter aberto, estabelece sim uma relação conceitual com essa "estrutura arquitetônica - também - elementar". Na "forma base" destacada neste trabalho, o elemento varanda - a modo de pátio - conecta as partes da composição, reestabelecendo a unidade do partido agora decomposto. No entanto, no caso em estudo a atitude é inversa à da casa-pátio. Os volumes não se recolhem formando um espaço introvertido. Ao invés de um movimento de retraimento há um movimento de expansão e de extroversão. Se a integração do pátio com o exterior se dá em direção ao zênite, a varanda se expande em direção ao horizonte. A "varanda conectora" assim é fruto de um momento específico da arquitetura, um momento da abertura e "decomposição" dos tipos tradicionais, das oportunidades de partidos compostos 
com fragmentos de outros partidos, de outros tipos. É filha de uma modernidade onde o recolher-se e o mostrar-se, o íntimo e o exposto, o público e o privado enfim, estão sempre atuando em um jogo dialético.

O que destacamos aqui nesse artigo, é o valor da ideia de série tipológica. Séries que podem ser formadas a partir de "estrutura arquitetônicas elementares" que vão se transformando e/ou se organizando com outras estruturas elementares - de diferentes tempos - e conformando diferentes partidos. Mas há algumas estruturas que são mais determinantes, mais definidoras de uma forma-base que se consolida. Assim o pátio, o claustro, assim a varanda conectora.

\section{REFERÊNCIAS}

ARGAN, G. C. Sul concetto di tipologia architettonica. In: ARGAN, C. G. Progetto e destino. Milano: Il saggiatore, 1965.

BRANDÃO, H. C. L.; MARTINS, A. M. M. Varandas nas moradias brasileira: do período de colonização a meados do século XX. Revista tempo de conquista, n. 1, mar. 2007. Disponível em: http://www.revistatempodeconquista.com.br/documents/RTC1/HELENALACE1.pdf. Acesso em agosto/2016.

COMAS, C. E. Protótipo e monumento, um ministério, o ministério. Projeto, São Paulo, n. 102, p. 136-149, 1986.

GOODWIN, P. L. Brasil Builds. Nova York: Museu de Arte Moderna, 1943.

CORONA MARTíNEZ, A. Ensayo sobre el proyecto. Buenos Aires: CP67, 1991.

LEMOS, C. A. C. A Casa Brasileira. São Paulo: Contexto, 1996.

MARTÍ ARÍS, C. Las variaciones de la identidad: ensayo sobre el tipo en la arquitectura. Barcelona: Colegio de Arquitectos de Cataluña, 1993.

MARTÍ ARÍS, C. La casa binuclear según Marcel Breuer: el patio recobrado. DPA: Documents de Projectes d'Arquitectura, n. 13, 1997, p. 4651. Disponível em: http://upcommons.upc.edu/handle/2099/12168?locale-attribute=es. Acesso em setembro/2016

MINDLIN, H. E. Arquitetura moderna no Brasil. Rio de Janeiro: Aeroplano, 2000

\section{NOTAS}

(1) Pesquisa "A casa contemporânea brasileira: regra e transgressão tipológica no espaço doméstico", coordenada por Ana Elisia da Costa - UFRGS - e com participação da UFPel, UFPB, UEG e UCS. Disponível em https://www.ufrgs.br/casacontemporanea/.

(2) Embora a cobertura plana tenha sido a inicialmente adotada, a partir dos anos 40, o telhado se instala definitivamente na residência moderna brasileira como parte de um princípio representação do "espírito do lugar" e de conexão com a tradição.

(3) A Casa em Praia Preta possui ainda um outro volume no fundo do terreno que abriga casa do caseiro e/ou apartamentos para hóspedes. Essa parte da casa, por estar separada do corpo principal da habitação não será considerada na análise aqui realizada.

NOTA DO EDITOR (*) O conteúdo do artigo e as imagens nele publicadas são de responsabilidade do(s) autor(es). 